\title{
Primary Myelodysplastic Syndrome in Jordan: A Single-Centre Experience
}

\author{
Abdalla Awidi $^{\mathrm{a}}$ Ahmad Magableh $^{\mathrm{a}}$ Ziad Taimeh $^{\mathrm{a}}$ Hashim Ayyad $^{\mathrm{a}}$ \\ Nazzal Bsoul ${ }^{a}$ Musleh Tarawneh ${ }^{b}$ \\ Departments of ${ }^{a}$ Hematology and Oncology and b Pathology, Jordan University Hospital, Amman, Jordan
}

\section{Key Words}

Myelodysplasia $\cdot$ Pancytopenia $\cdot$ Sideroblasts $\cdot$ Refractory anemia

\begin{abstract}
Objective: Study of the disease patterns and clinical evaluation of myelodysplastic syndrome (MDS). Subjects and Methods: A retrospective analysis was carried out on 85 patients, with MDS who were followed up over a period of 23 years at Jordan University Hospital, Amman, Jordan. Cases were analyzed according to the French, American and British Classification. Results: Of the 85 patients, 42 (49.4\%) were females and 43 (50\%) males; mean age was $59 \pm 19$ years (range 18-88). Most subtypes found in patients were refractory anemia (RA) in 27 (31.8\%) and RA with excess blasts (RAEB) in 28 (32.9\%). Adverse prognostic indicators were RAEB subtype and requirement for blood transfusion. Conclusion: Our findings showed that MDSs appeared at a younger age and tended to be of the aggressive subtype. Chronic myelomonocytic leukemia subtype seemed to appear dominantly in men.

Copyright $\odot 2009$ S. Karger AG, Basel
\end{abstract}

\section{Introduction}

Myelodysplastic syndrome (MDS) comprises a spectrum of heterogeneous clonal hematopoietic disorders characterized by dysplastic and ineffective blood cell production, resulting in chronic cytopenia, abnormal cellular maturation and a variable risk of transformation into acute leukemia [1-3]. These disorders may arise de novo or years after exposure to potentially mutagenic treatments such as irradiation and chemotherapy [4]. The incidence of de novo MDS is variable. The objective of this study was to document the disease pattern and evolution in Jordan.

\section{Subjects and Methods}

The medical records of all patients with a laboratory diagnosis of MDS at Jordan University Hospital, Jordan, between January 1, 1985 and the end of 2007 (23 years) were reviewed. The following data were gathered: gender, age, presenting symptoms, blood transfusions, French-American-British (FAB) Classification, blood count, serum ferritin and lactate dehydrogenase (LDH), blasts in bone marrow, cytogenetics, progress to acute leukemia and survival.

For the purpose of calculating the length of follow-up and survival, the period until the last documented visit was taken and approximated to the nearest month. If the patient was lost to follow-up or was transferred somewhere else, the last visit was con-

\section{KARGER}

Fax +41613061234

E-Mail karger@karger.ch

www.karger.com
(C) 2009 S. Karger AG, Basel

$1011-7571 / 09 / 0185-0351 \$ 26.00 / 0$

Accessible online at:

www.karger.com/mpp
Abdalla Awidi, MD, FRCP

Department of Hematology and Oncology, Jordan University Hospital

Q.R. Street, PO Box 9240, Amman 11191 (Jordan)

Tel. +962 65355000 ext. 23453, Fax +962 65356746

E-Mail aawidi@yahoo.com or aabbadi@ju.edu.jo 
Table 1. Gender, age and frequency according to the FAB classification

\begin{tabular}{lcllllll}
\hline \multirow{2}{*}{ Gender } & Age, years & \multicolumn{7}{l}{ FAB subtypes } \\
\cline { 3 - 8 } & & RA & RAS & RAEB & RAEB-T & CMML & unclassified \\
\hline Male $(\mathrm{n}=43)$ & $57 \pm 18.4$ & 10 & 6 & 12 & 5 & 8 & 2 \\
Female $(\mathrm{n}=42)$ & $58.8 \pm 19.5$ & 17 & 4 & 16 & 3 & 2 & 0 \\
Total $(\mathrm{n}=85)$ & $58 \pm 19$ & 27 & 10 & 28 & 8 & 10 & 2 \\
\hline
\end{tabular}

Table 2. Blood findings, serum ferritin, $\mathrm{LDH}( \pm \mathrm{SD})$ at presentation, and blood transfusions during the period of follow-up

\begin{tabular}{|c|c|c|c|c|c|c|}
\hline & \multicolumn{2}{|l|}{ Cumulative } & \multicolumn{3}{|l|}{ Subtype } & \multirow[t]{2}{*}{ Total $^{\mathrm{a}}$} \\
\hline & CMML & $\mathrm{RA}$ & RAEB & RAEB-T & RAS & \\
\hline Age, years & $60.7 \pm 12.2(10)$ & $59.9 \pm 19.2(27)$ & $58.6 \pm 19.5(28)$ & $52.0 \pm 20.9(8)$ & $52.1 \pm 24.5(10)$ & $57.8 \pm 19.3(83)$ \\
\hline $\mathrm{Hb}, \mathrm{g} / \mathrm{dl}$ & $8.4 \pm 2.1(10)$ & $8.7 \pm 1.8(27)$ & $9.2 \pm 2.2(28)$ & $8.3 \pm 2.3(8)$ & $8.7 \pm 1.2(10)$ & $8.8 \pm 1.9(83)$ \\
\hline Platelets $\times 10^{3} / \mu \mathrm{l}$ & $164.3 \pm 141.1(10)$ & $249.8 \pm 184.5(27)$ & $153.1 \pm 82.2(28)$ & $60.3 \pm 53.3(8)$ & $204.2 \pm 103.7(10)$ & $183.1 \pm 141.3(83)$ \\
\hline $\mathrm{WBC}, \times 10^{3} / \mu \mathrm{l}$ & $5.8 \pm 3.6(10)$ & $6.1 \pm 4.2(27)$ & $6.4 \pm 4.2(28)$ & $4.9 \pm 3.4(8)$ & $5.3 \pm 2.0(10)$ & $5.9 \pm 3.8(83)$ \\
\hline LDH, IU/l & $488.4 \pm 324.7(10)$ & $413.2 \pm 328.8(27)$ & $538.7 \pm 446.2(28)$ & $318.2 \pm 249.2(8)$ & $481.6 \pm 302.1(10)$ & $463.7 \pm 362.8(83)$ \\
\hline Ferritin, ng/ml ${ }^{\mathrm{b}}$ & $1,035 \pm 324(7)$ & $396.2 \pm 381.7(25)$ & $452.1 \pm 489.1(23)$ & $346.8 \pm 310.9(6)$ & $715.7 \pm 308.9(6)$ & $506.3 \pm 445.4(67)$ \\
\hline $\begin{array}{l}\text { Blood transfusion (only } \\
\text { for patients who received } \\
\text { blood units), units/month }\end{array}$ & $4.6 \pm 3.2(9)$ & $2.1 \pm 1.7(17)$ & $3.9 \pm 2(23)$ & $2.9 \pm 1.9(8)$ & $2 \pm 1.0(8)$ & $3.2 \pm 2.3(65)$ \\
\hline
\end{tabular}

sidered for the length of follow-up. Death was documented if it occurred at the university hospital or if it was documented by relatives. If death was not documented as such, it was entered as unknown. Patients diagnosed with MDS at another hospital were excluded because of difficulty in calculating the follow-up period and/or survival.

\section{Results}

A total of 85 patient records were reviewed; there were 42 (49.4\%) females and 43 (50.6\%) males; ages ranged from 15 to 88 years; mean age of males was $63 \pm 16.2$ years, and mean age of females was $53 \pm 20.7$ years. As shown in tables 1 and 2, the most frequently seen subtypes were refractory anemia with excess blasts (RAEB) and refractory anemia (RA). Females had more often RA and RAEB while males had more often chronic myelomonocytic leukemia (CMML), RA with ringed sideroblasts (RAS) and RA with excess blasts in transformation (RAEB-T).

The mean survival of patients with RA and RAEB was $59.7 \pm 9$ and $30.7 \pm 4$ months, respectively. The mean survival of patients who did not receive any blood transfusions was $55.9 \pm 8$ months and that of patients who received blood transfusions was $31.8 \pm 4.1$ months.

Cytogenetic investigations were documented in $26 \mathrm{pa}-$ tients since they have become available only recently. Of these, 16 patients had normal cytogenetics, 5 with deletion of the long arm of chromosome 5 (5q-), 3 with complex chromosomal abnormalities and the 2 remaining had cytogenetic abnormalities. Twenty patients (11 males and 9 females) transformed into acute myeloid leukemia during the follow-up period.

At presentation, there was no difference in the hemoglobin level between males and females: $9.4 \pm 5.9 \mathrm{~g} / \mathrm{dl}$ in males and $9 \pm 2 \mathrm{~g} / \mathrm{dl}$ in females. Platelet count at presentation was higher in males $\left(280.7 \pm 131 \times 10^{9} / \mathrm{l}\right)$ than in females $\left(82.3 \pm 52.2 \times 10^{9} / 1\right)$. Males required a mean of 3.6 units of blood transfusion per month while females required a mean of 2 units per month. Patients were followed up for 2,144 patient-months with a mean of 25.2 months and a range of 1-127 months. During the followup period, there were 40 documented deaths: 22 males and 18 females. Among the males, death occurred in the 


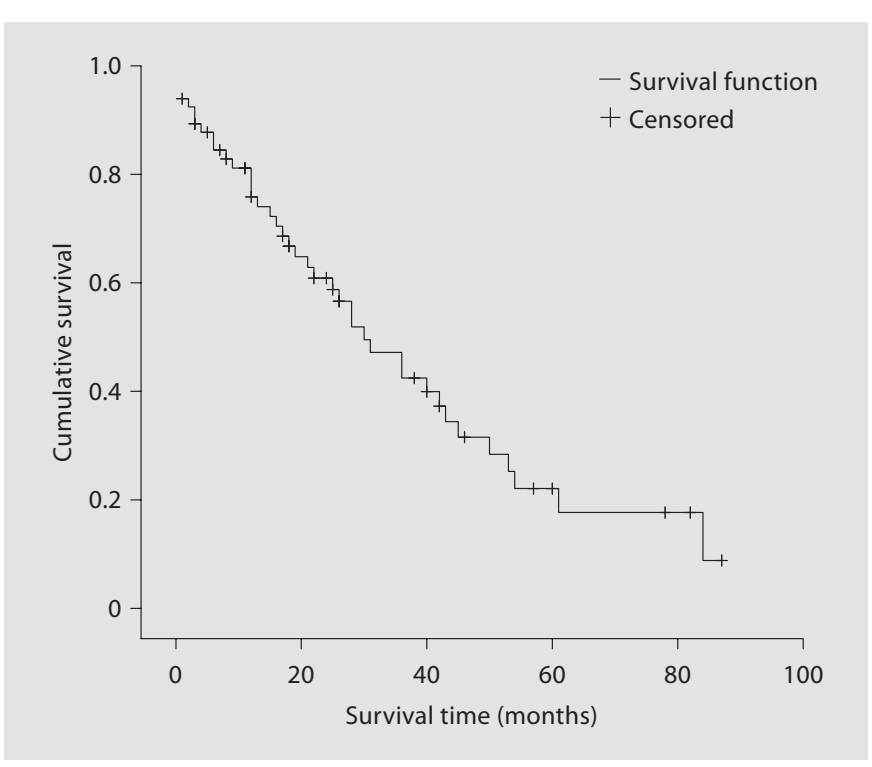

Fig. 1. Overall Kaplan-Meier survival of 66 patients whose survival is known.

following subtypes: 12 died of RAEB, 3 of CMML, 3 of RAEB-T, and 2 each of RA and RAS. Among the females, 9 died of RAEB, 4 of RA, 2 each of CMML, RAEB-T, and 1 of RAS. Mean patient survival was $36.96 \pm 4$ months as shown in the Kaplan-Meier survival curve of figure 1. There were enough patients for calculation of survival rates only for the RA and RAEB subtypes as shown in figure 2 . The mean survival rates of patients with RA and RAEB were $59.74 \pm$ (SE) 9 and $30.76 \pm$ (SE) 4 months, respectively; the difference is statistically significant $(\mathrm{p}<$ 0.029 ). The mean survival rates for patients with and without blood transfusion were $31.85 \pm$ (SE) 4.17 and $55.89 \pm$ (SE) 8.42 months, respectively; the difference is also statistically significant $(\mathrm{p}<0.023)$ as shown in figure 3. No statistical difference was observed in the survival of patients who had higher than normal LDH levels compared to those with normal LDH levels ( $\mathrm{p}=0.583$ ) as shown in figure 4 .

\section{Discussion}

MDS is considered an important condition in developed nations, with a reported crude annual incidence of 4.1 per 100,000 in Germany and the incidence is increasing as the population ages [5]. Fortunately, the development of new therapies such as lenalidomide, oral iron chelators, hypomethylating agents a well as erythropoie-

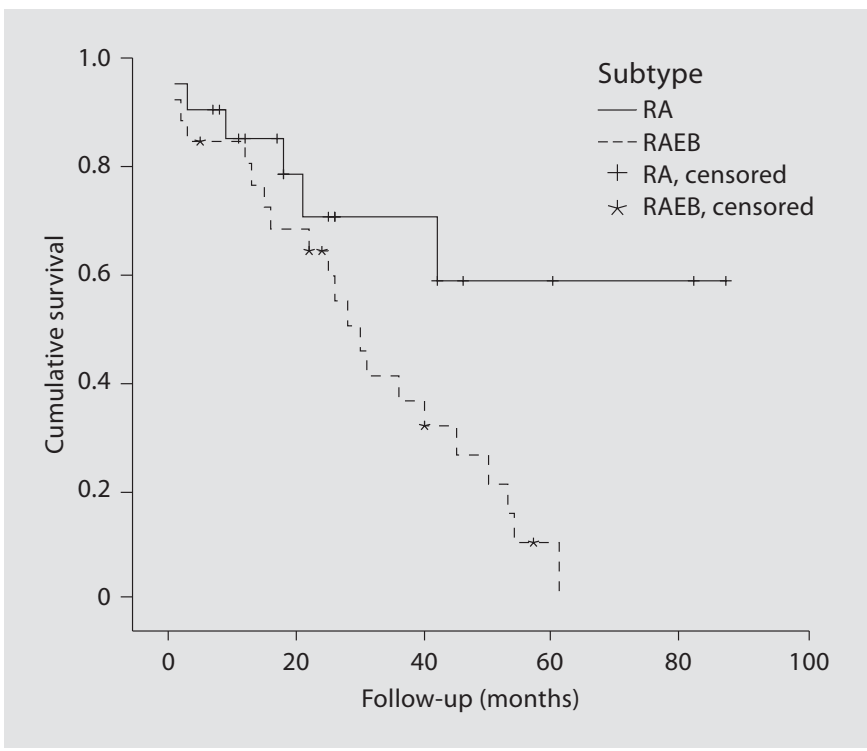

Fig. 2. Kaplan-Meier survival curves of 21 RA and 26 RAEB patients.

tin are helping to improve the outcome of this disease and the patients' quality of life [6].

In developing nations, MDS has not been studied and little is known about its epidemiology, behavior and prevalence. This retrospective study reviewed the experience of a large university center in Jordan. In view of the small number of cases reviewed, the clinical spectrum of this syndrome in this developing nation, where the population is dominantly very young, is uncertain and will need to be studied prospectively. The age of onset of MDS is between 60 and 70 years without any gender preference nor a younger age of onset $[1,2,7-13]$. Consequently, MDS is considered a disease of aging $[14,15]$. Yet in our study, the age of onset is younger than reported in the literature $[14,15]$.

Our findings concerning the incidence of RAEB (33\%) and RA (32\%) are similar to previously reported values [16]. The incidence of CMML and RAS (11.7\% each) is also comparable to that reported in the literature [17]. The observation that CMML was predominantly observed in men in this study, with a 4:1 male to female ratio, is different from that reported in the literature, where the male to female ratio is $2: 1$ [17]. The reason for this is unclear and warrants further study in the future.

Survival according to FAB subtype in this study is consistent with that reported in the literature [12]: survival was the longest in patients with RA while survival was the shortest in patients with RAEB. Because of the 


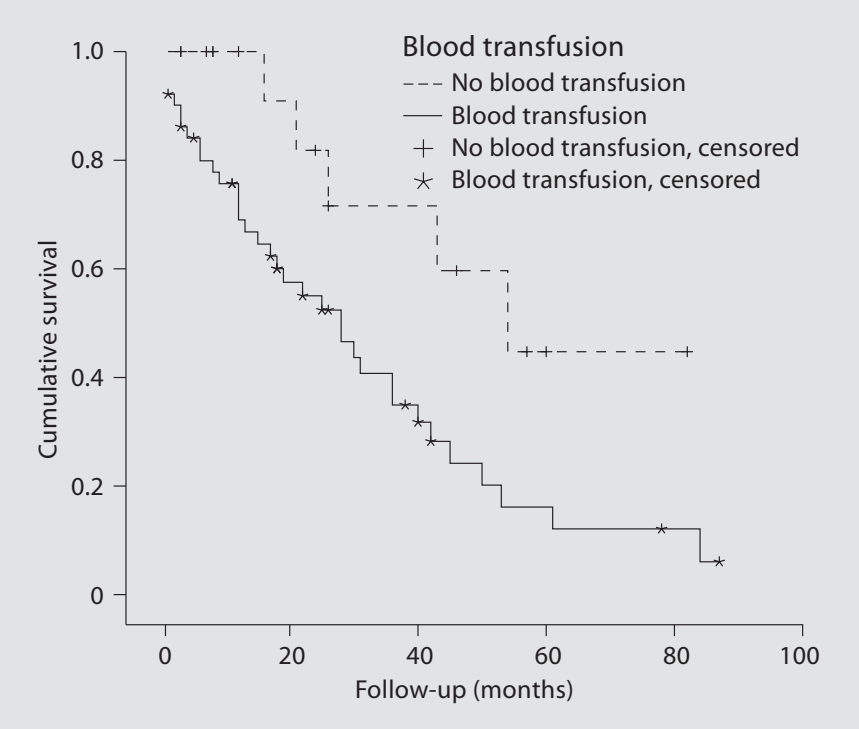

Fig. 3. Kaplan-Meier survival curve of 51 patients who received blood transfusions and 15 patients who did not receive any blood transfusion.

small number in other subtypes, statistical evaluation of survival was not considered meaningful. Since cytogenetic studies were carried out only in a few patients, the International Prognostic Score (IPSS) could not be applied.

The survival of transfused patients was shorter compared with patients who were not transfused; this observation is consistent with Malcovati's [18] findings. The contribution of LDH level to survival was not evident in this study due to the small number of patients and is different from that reported in the literature [19].

The significance of high serum ferritin at presentation in MDS in this study is not well understood, and its prog-

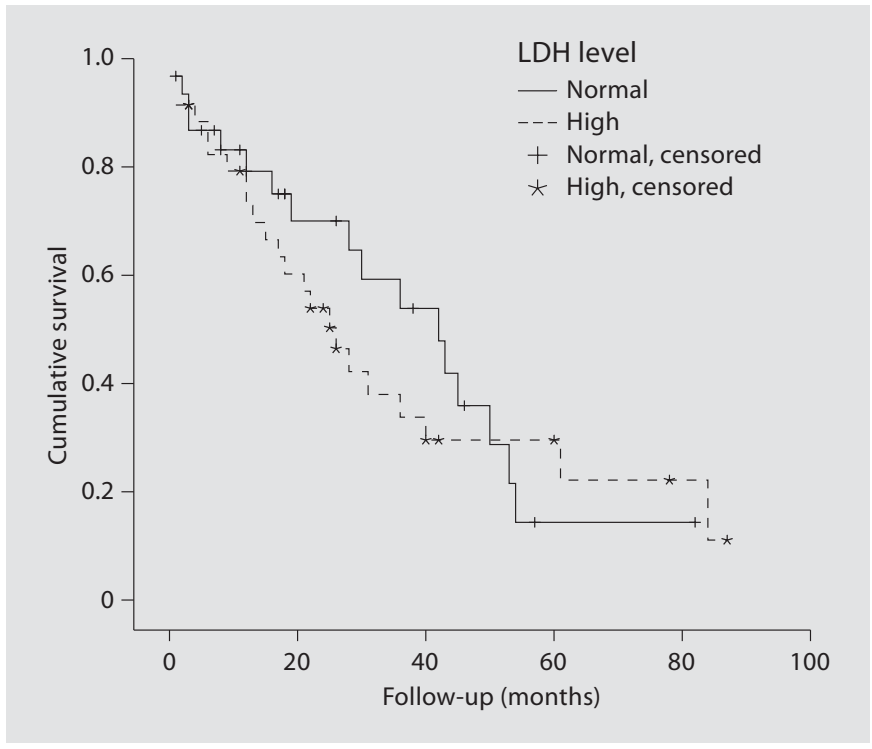

Fig. 4. Kaplan-Meier survival curves of 29 patients with normal and 35 patients with higher than normal LDH. There is no statistical difference between the two groups.

nostic significance remains to be clarified. However, in the setting of repeated transfusions, iron overload may play an important role in shortening survival unless proper iron chelation is implemented with iron chelators as part of the care for MDS [20].

\section{Conclusion}

MDS in Jordan appeared to affect younger age groups, and tended to be of the aggressive subtype. Blood transfusion and possibly iron overload seem to be associated with shorter survival.

\section{References}

1 Greenberg P: The smoldering myeloid leukemic states: clinical and biologic features. Blood 1983;61:1035-1044.

-2 Doll D, List A: Myelodysplastic syndromes. West J Med 1989;151:161-167.

3 Albitar M, Manshouri T, Shen Y, Liu D, Beran M, Kantarjian HM, Rogers A, Jilani I, Lin CW, Pierce S, Freireich EJ, Estey EH: Myelodysplastic syndrome is not merely 'preleukemia’. Blood 2002;100:791-798.
Levine E, Bloomfield C: Leukemias and myelodysplastic syndromes secondary to drug, radiation, and environmental exposure. Semin Oncol 1992;19:47-84.

5 Aul C, Gattermann N, Schneider W: Age-related incidence and other epidemiological aspects of myelodysplastic syndromes. Br J Haematol 1992;82:358-367.

6 Nimer SD: Myelodysplastic syndromes. Blood 2008;111:4841-4851.
Foucar K, Langdon R 2nd, Armitage J, Olson D, Carroll T: Myelodysplastic syndromes. A clinical and pathologic analysis of 109 cases. Cancer 1985;56:553-561.

8 Vallespi T, Torrabadella M, Julia A, Irriguible D, Jaen A, Acebedo G, Acebedo G, Triginer J: Myelodysplastic syndromes: a study of 101 cases according to the FAB classification. Br J Haematol 1985;61:83-92. 
$>9$ Tricot G, Vlietinck R, Boogaerts M, Hendrickx B, De Wolf-Peeters C, Van den Berghe $\mathrm{H}$, Ver Wilghen RL: Prognostic factors in the myelodysplastic syndromes: importance of initial data on peripheral blood counts, bone marrow cytology, trephine biopsy and chromosomal analysis. Br J Haematol 1985;60: 19-32.

10 Kuriyama K, Tomonaga M, Matsuo T, Ginnai I, Ichimaru M: Diagnostic significance of detecting pseudo-Pelger-Huet anomalies and micro-megakaryocytes in myelodysplastic syndrome. Br J Haematol 1986;63: 665-669.

$>11$ Knapp R, Dewald G, Pierre R: Cytogenetic studies in 174 consecutive patients with preleukemic or myelodysplastic syndromes. Mayo Clin Proc 1985;60:507-516.

12 Jacobs R, Cornbleet M, Vardiman J, Larson R, Le Beau M, Rowley J, et al: Prognostic implications of morphology and karyotype in primary myelodysplastic syndromes. Blood 1986;67:1765-1772.
13 French registry of acute leukemia and myelodysplastic syndromes: age distribution and hemogram analysis of the 4,496 cases recorded during 1982-1983 and classified according to FAB criteria. Groupe Français de Morphologie Hématologique. Cancer 1987; 60:1385-1394.

14 Bader-Meunier B, Miélot F, Tchernia G, Buisine J, Delsol G, Duchayne E, Lemerle S, Leverger G, de Lumley L, Manel AM: Myelodysplastic syndromes in childhood: report of 49 patients from a French multicentre study. French Society of Paediatric Haematology and Immunology. Br J Haematol 1996;92: 344-350.

15 Passmore S, Hann I, Stiller C, Ramani P, Swansbury G, Gibbons B, Reeves BR, Chessells JM: Pediatric myelodysplasia: A study of 68 children and a new prognostic scoring system. Blood 1995;85:1742-1750.

16 Greenberg P: Myelodysplastic syndrome; in Hoffman R, Benz EJ, Shattil SJ (eds): Hematology: Basic Principles and Practice, ed 3. New York, Churchill Livingstone, 2000, p 1106.

-17 Phekoo K, Richards M, Møller H, Schey S: South Thames Haematology Specialist Committee. The incidence and outcome of myeloid malignancies in 2,112 adult patients in southeast England. Haematologica 2006;91: 1400-1404.
18 Malcovati L: Impact of transfusion dependency and secondary iron overload on the survival of patients with myelodysplastic syndromes. Leuk Res 2007;31(suppl 3):S2S6.

19 Germing U, Hildebrandt B, Pfeistocker M, Nosslinger T, Valent P, Fontasch C, Lübbert M, Haase D, Steidl C, Krieger O, Stauder R, Giagounidis AA, Strupp C, Kündgen A, Mueller T, Haas R, Gattermann N, Aul C: Refinement of the international prognostic scoring system (IPSS) by including LDH as an additional prognostic variable to improve risk assessment in patients with primary myelodysplastic syndromes (MDS). Leukemia 2005;19:2223-2231.

20 Porter J, Galanello R, Saglio G, Neufeld E, Vichinsky E, Cappellini M, et al: Relative response of patients with myelodysplastic syndromes and other transfusion-dependent anaemias to deferasirox (ICL670): a 1-year prospective study. Eur J Haematol 2008;80: 168-176. 